\title{
The Role of Jordanian Secondary School Teachers in Educating Students About Cyber Bullying and the Difficulties They Face in That
}

\author{
Rawan Yousef Al-Slehat Prof. Muhammad Saleem Al-Zboon
}

\begin{abstract}
:
The study aimed to reveal the role of Jordanian secondary school teachers in educating students about cyber bullying and the difficulties they face in this. In order to achieve the aims of the study, the descriptive survey method was used for its suitability to the nature of this study, and the study adopted a questionnaire developed to collect data, and it was distributed on a random sample that included 173 teachers from Jordanian government schools in the second Amman Directorate, The study found that the role of Jordanian secondary school teachers in educating students about cyber bullying was average, and the results also showed that the difficulties facing them in this came with an average degree, As the most prominent of these difficulties facing the teacher was the fear of the victim of bullying from talking to others that he was bullied. The study recommended the necessity of enhancing the teacher's role in combating the phenomenon of electronic bullying by providing enough time outside classroom classes to educate students and motivate teachers to take this positive role. In addition to encouraging students to disclose the incidents of electronic bullying that they have been exposed to, because students' fear of speaking to others increases the phenomenon and makes it difficult for teachers or parents to deal with.
\end{abstract}

Keywords: cyberbullying.

DOI: $10.7176 / \mathrm{JEP} / 11-8-15$

Publication date:March $31^{\text {st }} 2020$

\section{Introduction:}

All educational institutions are concerned with raising and nurturing individuals and preparing them for life. The educational process mediates all their relationships, organizes their behavior and makes it consistent and consistent despite life changes. It works hard to reach a good society that includes good individuals, educated people, educated about their religion and worldly affairs, and they have the ability to adapt to social changes and technology around them, It also instills in them good behaviors that lead them to solve their problems without fanaticism and violence, respect for others and adherence to the laws and regulations in force in society.

The school is one of the most important educational institutions that society has established to educate its children according to programs, plans and curricula that are compatible with its goals, as it transmits cultural heritage from one generation to another, It performs a specific function in preserving the cohesion of society, and providing its members with the knowledge, science and good values that contribute to their development and refine their behavior and self-esteem, It helps them build relationships with their peers on the basis of respect, understanding, and peaceful coexistence, away from intolerance and violence, so that they become a righteous and effective individual in society (Nasser, 2011).

Of course, it must be within the school the appropriate climate that prepares it for the way to carry out its basic function and build the healthy personality of the student and formulate it in the required image, Within a balanced educational and ethical system, away from all forms of violence, intolerance and victimization, so that they are able to deal with the requirements of change consciously and rationally This reflects positively on the community ladder (Al-Assaf and Al-Sarayrah, 2010). The important role of the teacher in educating and spreading peace among the community members, especially at the present time (Quezada and Romo, 2004), is not hidden.

However, the spread of the phenomenon of aggression and violence in all its forms in schools, especially among high school students, is constantly increasing, as students at this critical transitional age are subject to negative behaviors and practices that are not acceptable in or outside the school, Multiple forms, types, intensity, intensity, and examples of which are bullying or bullying, which is a form of aggression and violence. Bullying is a dangerous phenomenon that quickly penetrates among students, It is a deliberate and repeated attack that occurs between two different students in terms of strength, and its negative effects are not limited to the bully student or the student who is a victim of bullying, but it reaches the social entity in general and educational in particular. Because bullying carries physical, verbal, psychological, emotional or even electronic harm, it has repercussions on the school environment and the social and security construction of society (Alwan, 2016).

Accordingly, the interest of educators and specialists in educational institutions has increased with the phenomenon of bullying, according to its devastating effects on students, school and the whole society, especially since this phenomenon brings negative ideas to students Like attempted suicide, as a result of the aggressive behaviors and actions that the bully exerts on the victim from harassment, such as insults, threats, beating, and intimidation, as the bully shows stubbornness and social harmony And anti-social behaviors, to reach a degree of 
complacency and control over the victim (customer and Zaghloul, 2016), As for the student who is a victim of bullying, he feels low satisfaction with himself, leading to a loss of self-confidence, isolation and weakness, and signs of depression and loneliness appear on him, which affects his psychological state and his social relationships (Al-Qahtani, 2015).

Whereas, the enormous technological changes and developments that we are living in today lead to the creation of electronic means and tools that facilitate the process of social communication, drawing the attention of the world in all its categories, And it has worked to bring about fundamental changes in the social relationships of individuals, their interactions and their methods of communication, as social media has become online, A social platform for all individuals, regardless of their age and levels, spend most of their time on them, and allows them to communicate, communicate and express their opinions without spatial or temporal restrictions, Which at the same time has become a means for some to use bullying, whether verbally or in writing (Mohammadi and Kheda, 2018).

Thus, the transformation of traditional bullying, known in reality, into a virtual reality, resulted in what is known as electronic bullying, which undoubtedly carries serious repercussions on the relationships of individuals and their interactions that affect societal peace.

Despite the multiple definitions of cyberbullying, they are combined as direct, indirect or intentional hostile behavior (Baldry, Farrington and Sorrentino, 2019). The bully is practiced by the victim, and it comes in a rhythm of various types of psychological and social abuse, through electronic means and applications via the Internet or cell phones By sending messages containing harassment, insult, insults, and defamation (Ortega et al., 2012).

From the previous definition, it is clear that cyberbullying is a behavior or act performed by a bully, preceded by a deliberate and repeated intention and intention to harm others. Using multiple electronic methods, such as hacking personal accounts on social media and trying to exploit personal data and photos published through these accounts And spreading news and lies about the owners of these accounts, and sending threatening messages via smart phones or e-mail, with the aim of imposing control over the victim.

Thus, cyberbullying differs from traditional bullying by practicing through cyberspace, as the bully and the victim do not meet face to face, Because it is using phone calls, messages, e-mail and posting offensive images and videos on social media, With the aim of mocking the victim, threatening him, blackmailing him and denigrating his reputation, his influence inside and outside the school continues without supervision, and the bully can share with other people by following and sharing photos or videos and admiring them, This increases the ability of the bully to conceal his identity and the difficulty of revealing his identity (Al-Shennawi, 2014). Thus the incidence of cyber bullying outside the school is greater, This reduces the level of responsibility on the bully, and makes it difficult for the victim to easily get rid of it, to control the content and to delete or avoid it, especially since it is in the vast cyberspace (Smith, Mahdavi, Carvalho, Fisher, Russell, and Tippett, 2008).

The causes of cyberbullying are largely related to mental disorders and behavioral problems that high school students are exposed to. Adolescents try to project their identity, break everything that is familiar, and rebel against social laws, To prove themselves and enhance self-confidence, which makes them in constant conflict with their social environment, the nature of students at this stage tends to love the excitement and experience everything that can be tried, This makes them quick to respond to all the stimuli facing them, and resort to modern electronic applications and free their energies through them (Alwan, 2016).

Bullying is classified as a global problem with negative effects not on the scale of small societies such as school and university, but its effects extend to the whole society. Perhaps one of the most important of these negative effects for students is that it harms their mental health, in that it inherits cases of social anxiety, insomnia, feelings of humiliation, sadness and anger, It harms the emotional health and sense of safety after the student, in addition to the decline in the achievement level of the student and his absence from school, which affects his relationship with his colleagues, teachers, family and all members of society.

In the same context, it has been found that cyberbullying is one of the underlying causes of frustrations and suicide attempts among school students (Messias, Kindrick and Castro, 2014), Likewise, high levels of depression among them (Turner, Exum, Brame and Holt, 2013).

Secondary school teachers face a lot of difficulties in educating students about the nature of electronic bullying and its harms, effects and dangers, which is limited by their knowledge of using applications and technical means that will interest students in their teens. Also, electronic bullying cannot be detected easily unless the victim student talks about his bullying in front of his teacher, in addition to not allocating class classes to present the problems and issues facing students based on dialogue, discussion, respect for opinion and acceptance of the other. The occurrence of electronic bullying outside the school most of the time leads to difficulty in identifying the personality of the bully student, thus the teacher faces a major challenge in contributing to reducing the severity of this phenomenon.

In light of the foregoing, it can be said that the role of Jordanian secondary school teachers by educating students about cyber bullying is the need to work to establish the foundations of a safe and socially supportive school environment, instilling in students the correct concepts That calls for harmony, understanding, tolerance, 
dialogue and mutual respect and adherence to them in light of social changes and technology, and to educate students about safe dealing with electronic applications, By taking full care and caution in electronic accounts, all social networks, email and others have a privacy-enhancing feature that gives greater protection, To avoid compromising information in a way that harms the user to reach a peaceful and safe society without bullying.

\section{The study problem and its questions:}

The need for this study emerged in the light of the attention that the subject of electronic bullying has received among specialists and educational experts in recent times. This is due to the negative effects of this type of bullying on the bullies themselves, victims and society as a whole. And the difficulty of controlling it, especially in light of the widespread spread of social media, its availability, accessibility and use by all members of society. This great spread is accompanied by serious damage to society, which is represented by an increase in violence, hatred and hatred among members of society. According to the important role that secondary school teachers play in refining and highlighting the personality of students, as the secondary stage is considered one of the critical stages in students 'lives due to the changes in perception, behavior and ideas. Which necessitates taking care of students at this stage and forming their proper attitudes and developing the social attributes that guide them to the correct peaceful interaction with members of society in light of the technological changes taking place today. Accordingly, the study seeks to answer the following questions:

1. What is the role of Jordanian secondary school teachers in educating students about cyber bullying from their point of view?

2. What are the difficulties facing the Jordanian secondary school teachers in raising awareness about cyber bullying?

\section{Objectives of the study:}

This study aims to define the role of Jordanian secondary school teachers by educating students about electronic bullying from their point of view, and to identify the difficulties that secondary school teachers face in raising awareness of this phenomenon.

\section{The importance of studying:}

The importance of the study emerges through the identification of the role of Jordanian secondary school teachers in educating students about electronic bullying, based on the important role of teachers in forming the students 'personality, sensitizing them to concepts and providing them with the correct values that contribute to the development of their personalities and societies, Especially in our present time in light of the technological revolution and the spread and development of social media, which has become a platform that allows many to practice all forms of bullying on others without censorship and restrictions. It is hoped that the following authorities will benefit from the current study:

- The Ministry of Education, by applying the results of the study in the face of electronic bullying and its prevention by scientific methods and methods, And to develop educational policies that ensure the creation of a safe school environment so as to achieve societal peace, and Programs that replace bullying with mutual trust and constructive cooperation.

- Secondary school teachers by enhancing their role in awareness of electronic bullying, by focusing on the subject of electronic bullying and clarifying its risks through holding educational programs, classes and lectures that contribute to modifying and evaluating students 'behavior to mitigate the severity of their electronic bullying, and Reducing its effects on society, which contributes to achieving social peace.

- Researchers, through benefiting from this study and working to enrich the knowledge side of scientific studies related to the subject of electronic bullying because of its importance and novelty, And also benefit from the study tool that will be developed.

\section{Conceptual and procedural definitions:}

For the purposes of achieving its objectives, the study adopts the following terms:

- Electronic bullying (convention): is the use of the Internet and other electronic communication devices, and social media by individuals to insult, threaten, or intentionally harm another person by sending or publishing texts or harmful images (Tokunaga, 2010, p.281).

- Electronic bullying (procedural): a set of practices and behaviors practiced by high school students through the use of modern means of communication and its various applications, which lead to harm and harm to others, and was measured through the tool that researchers developed.

The limits of the study:

The study limits are as follows:

- Objective limits: The study examined the role of Jordanian secondary school teachers in educating students about 
cyber bullying, its implications for the social ladder, and proposals for its development.

- Human boundaries: The study was limited to a sample of secondary school teachers in Jordanian government schools.

- Spatial boundaries: The study was limited to Jordanian government schools affiliated with the District Brigade

Directorate and the Wadi Seer District Directorate in the Capital Governorate.

- Time limits: The study was applied during the second semester of the academic year 2018/2019.

\section{Previous studies:}

The following is a presentation of some previous studies that dealt with the subject of the study, as they were classified into two axes: the first axis, Arab studies and the second axis, foreign studies. This is followed by a general comment on it, and then clarifying the degree of benefit from previous studies in the current study, and explaining what distinguishes the current study from previous studies, and it will be displayed chronologically from oldest to newest and as follows:

\section{First: Arab Studies:}

Othman and Ali (2014) conducted a study aimed at identifying the techniques of technological bulging among students of general education stages, in addition to knowing the types of technological bulging (text messages, email, phone calls, and sending pictures and videos) on a sample of 420 students From the elementary, middle and secondary levels of education in several schools in the governorates of Cairo and Qaliubiya, whose ages ranged between 11-18 years, A personal data form and a measure of technological bulging were used (prepared by researchers), and the results of general assumptions and sub-assumptions of electronic bullying methods (text messages, e-mail ...) indicated that there are statistically significant differences in the direction of secondary school students at the level of $(1 .,$.$) , And in the direction of the preparatory stage in the phone call at the level (1.,.).$

Al-Ammar (2016) conducted a study aimed at revealing the relationship between cyberbullying and internet addiction in light of some demographic variables among students of applied education in the State of Kuwait, The study sample consisted of (140) male and female students of applied education, whose ages ranged between (19) to (20) years. The scale of cyberbullying, Internet addiction and their psychometric properties have been designed, and the most important results of the study are the presence of statistically significant links between cyberbullying and internet addiction, And that males are more bullied by using electronic means and more addicted to the Internet compared to females.

Al-Enezi (2017) conducted a study aimed at identifying cyber bullying through social media and its relationship to school violence, and revealing the patterns of cyber bullying most prevalent on social media, and the patterns of school violence that are more prevalent, The researcher used the descriptive analytical method, and the study population consisted of two categories: third-grade students in public schools in Riyadh, by a sample that included (405) students, And counselors of students at government secondary schools in Riyadh, with a sample of (37) mentors. Among the most important findings of the study is the presence of a direct relationship with statistically significant between patterns of electronic bullying through social networking sites and patterns of school violence from the viewpoint of third-graders and mentors in government secondary schools in Riyadh.

Mohammedi and Khedeh (2018) conducted a study aimed at researching the nature of the impact of electronic violence on social networking sites on social relations among a random sample of university youth who use social networking sites consisting of (77) young people in Ouargla, Algeria. The study used the descriptive exploratory method and its data were collected by means of a questionnaire. Among the most important findings of the study is that the nature of the impact of electronic violence practiced on social media on social relations is negative. It has also been shown that the nature of this effect is not different for gender or age.

\section{Second. Foreign studies:}

Messias, Kindrick and Castro (2014) conducted this study to explore the relationship between cyberbullying, frustration, and suicide among high school students. The logistic regression was used to calculate the adjusted odds ratios, using a sample consisting of (15452) male and female students from secondary schools in the United States of America. The results of the study showed that females are more susceptible to cyberbullying than males, and the results also showed that cases of sadness and suicidal ideation were high among adolescents who were bullied.

Brown, Demaray and Secord 2014 study aimed to identify gender differences in e-violence and reveal the differences between traditional and e-violence practices In addition to investigating the relationship between traditional and electronic violence practices, and emotional and school outcomes. The study used the descriptive survey method, and the study sample consisted of (106) male and female students from the preparatory stage in the United States of America. The results indicated that there were no differences in exposure to cyber violence in light of the gender variable, And the existence of differences between traditional and electronic violence with being related variables to each other, and the results of the study also showed the existence of gender differences in terms of exposure to electronic violence practices and emotional and school outcomes, as it was found that females are more suffering from these behaviors compared to males. 
Athanaside, Kamretos, Basalti, and Baldry (Athanaside, Kamariotis, Psalti, Baldry, \& Sorrention, A. 2015) conducted a study aimed at determining the nature of the relationship between Internet addiction and cyber violence or receiving electronic threats in adolescents in Greece, And by using a scale consisting of 44 questions that were divided into three parts, the study sample consisted of (314) students from the male secondary schools. Participants completed metrics for online study variables. Among the most important findings of the study was the decrease in the rates of committing dangerous behaviors via the Internet among adolescents in Greece compared to the rest of Europe. These students also assessed their participation in cyber violence, or what is known as cyberbullying, in the future in light of the unsafe use of the Internet.

Baldry, Farrington and Sorrention (2016) also conducted a study in Italy aimed at revealing the level of cyber bullying as a disordered behavior, To achieve the goals of the study and data collection, the e-bullying scale was used, and the students' experiences related to the Internet were collected, as the study sample consisted of (5058) middle and high school students, The results of the study showed that the level of bulging came high, and it is widespread among students. The results also indicated a statistically significant correlation between e-bullying and bullying in schools by $12.15 \%$, and a correlation between electronic bullying and school abuse by $7.4 \%$.

Leung, Wong and Farver (2018) conducted a study aimed at measuring the effect of electronic bullying on student satisfaction with life. The study used the descriptive analytical method and the data was collected by means of a questionnaire distributed to a sample of 312 male and female students from university colleges in China. The results showed that $58 \%$ of the participants were subjected to cyberbullying by others, and the results also showed a negative impact of cyberbullying on students 'satisfaction with life, noting that male students are more vulnerable to cyberbullying compared to females.

\section{Comment on previous studies and the location of the current study thereof:}

Previous studies dealt with topics related to the study variables represented by cyberbullying and its equivalent concepts (such as technological bullying and electronic violence), and the studies used different samples from Arab, foreign and Jordan countries. Likewise, the goals it sought to achieve and its results differed. In any case, the researcher believes that these studies have formed the primary source for a lot of important information, which will assist the current study in terms of its selection and define its problem, methodology and appropriate procedures to achieve its goals.

What distinguishes the current study from previous studies is that it is the first study - according to the researchers 'knowledge - that sheds light on the role of Jordanian secondary school teachers in educating students about electronic bullying, using the descriptive survey method by developing a questionnaire directed to secondary school teachers in Jordanian government schools in the second Amman Directorate .

This study comes as a positive step in explaining the role of stage teachers in raising awareness of cyber bullying, which contributes to providing fertile ground for implanting the values of coexistence and acceptance of the other among students, the optimal use of technology and avoiding its risks to reach a society free from violence.

\section{Study methodology and procedures: Study Approach:}

The study adopted the descriptive survey method used to describe the phenomenon under study, because it is the most appropriate method for the current study that seeks to know the role of Jordanian secondary school teachers in educating students of electronic bullying from their point of view.

\section{Study community:}

The study population consisted of all secondary school teachers in the government schools of the second Amman Directorate, which numbered (1440) male and female teachers.

\section{The study sample:}

The study sample will be chosen in two phases: In the first stage, 15 government schools were chosen intentionally, and in the second stage a sample consisting of (173) male and female teachers was chosen from the study community in a simple random way, the study tool was distributed, and the questionnaires were collected and analyzed.

\section{Study tool:}

The study tool was developed with reference to previous studies such as the study of: Asmaa Abdo (2016) and AlAnzi (2017) and Baldry, Farrington and Sorrention, 2016. And the response will be designed on the study tool according to the five-year scale according to the Likert five-year model as follows: a very large degree and it has (5) degrees, a large degree and it has (4) degrees, an average degree and has (3) degrees, A little degree and has two degrees, a very small degree and one degree. The following gradient was used for the purposes of the arithmetic mean on the study instrument as follows: the upper limit of alternatives (5), And the minimum for 
alternatives (1), and subtracting the maximum from the minimum equals (4) and then dividing the difference between the two limits by 3 levels as shown in the following equation:

$3 / 4$ levels (high, medium, low) $=1.33$

Thus, each paragraph with an mean of 1 to 2.33 represented a low score, and every paragraph with an average score of 2.34 to 3.67 represented an average degree, and every paragraph with an average score of 3.68 to 5 represented a high degree.

\section{Certify the tool:}

The tool was presented in its primary form to (5) arbitrators with jurisdiction, and they were asked to determine the degree of suitability of the paragraphs, their degree of clarity, and their linguistic integrity, List any proposed amendments and suggest paragraphs they deem necessary, and delete unnecessary paragraphs. An agreement criterion $(80 \%)$ was adopted by the jury committee to enable the amendment, deletion and addition. After returning the tool, the proposed amendments made by the arbitrators in their recommendations were made.

\section{Tool stability:}

The stability of the study instrument was verified during the extraction of the internal consistency of the instrument using the Cronbach's alpha coeffecient coefficient. As the value of the internal consistency coefficient of the questionnaire as a whole reached (0.95), and therefore the data obtained through it are suitable for measuring the variables, and are subject to a high degree of reliability.

\section{Study variables:}

First: independent variables:

- Estimates of Jordanian secondary school teachers in government schools in the second Amman Directorate on the paragraphs of the study tool.

Second: dependent variables:

- The role of Jordanian secondary school teachers in educating students about electronic bullying.

- High school teachers difficulties in educating students about cyber bullying.

\section{The results of the study and its discussion:}

Results of the first question, which read, "What is the role of Jordanian secondary school teachers in educating students about cyber bullying from their point of view?

To answer the first question, arithmetic averages and standard deviations for paragraphs (1-15) mentioned in the study questionnaire were calculated. Table (1) shows the results of that.

Table (1) arithmetic averages and standard deviations of the teacher's role in electronic bullying awareness

\begin{tabular}{|c|c|c|c|c|c|}
\hline \# & Paragraph & $\begin{array}{l}\text { Arithmetic } \\
\text { mean }\end{array}$ & $\begin{array}{l}\text { standard } \\
\text { deviation }\end{array}$ & Ranks & Availability \\
\hline 2 & $\begin{array}{l}\text { Make sure to educate students about safe handling } \\
\text { of electronic technologies and means. }\end{array}$ & 4.28 & 0.82 & 1 & High \\
\hline 1 & I educate students about what cyberbullying is. & 4.01 & 0.83 & 2 & High \\
\hline 9 & $\begin{array}{l}\text { I am interested in physical activities that stimulate } \\
\text { students' talents and devote themselves. }\end{array}$ & 3.95 & 0.94 & 3 & High \\
\hline 8 & $\begin{array}{l}\text { Work on the participation of civil society in fighting } \\
\text { the phenomenon of cyber bullying by holding } \\
\text { seminars inside the school. }\end{array}$ & 3.71 & 0.99 & 4 & High \\
\hline 14 & $\begin{array}{l}\text { Make sure to use tests to determine the level of } \\
\text { disorders (behavioral and emotional) in students. }\end{array}$ & 3.71 & 0.83 & 4 & High \\
\hline 15 & $\begin{array}{l}\text { Make sure to evaluate students' perverted behaviors } \\
\text { to protect them from falling prey to cyberbullying. }\end{array}$ & 3.64 & 0.77 & 6 & Medium \\
\hline 5 & Work on early monitoring of cyberbullying cases. & 3.51 & 0.90 & 7 & Medium \\
\hline 4 & $\begin{array}{l}\text { Contributes to an educational environment based on } \\
\text { mutual respect. }\end{array}$ & 3.46 & 0.53 & 8 & Medium \\
\hline 7 & $\begin{array}{l}\text { I encourage parents to visit the school periodically } \\
\text { to discuss issues related to cyber bullying. }\end{array}$ & 3.43 & 0.85 & 9 & Medium \\
\hline 6 & $\begin{array}{l}\text { I help students deal positively with their problems } \\
\text { away from any violence. }\end{array}$ & 3.36 & 0.36 & 10 & Medium \\
\hline 13 & $\begin{array}{l}\text { I am interested in spreading effective dialogue } \\
\text { method to enhance participation among students. }\end{array}$ & 3.29 & 0.81 & 11 & Medium \\
\hline
\end{tabular}




\begin{tabular}{|c|l|c|c|c|c|}
\hline$\#$ & Paragraph & $\begin{array}{l}\text { Arithmetic } \\
\text { mean }\end{array}$ & $\begin{array}{l}\text { standard } \\
\text { deviation }\end{array}$ & Ranks & Availability \\
\hline 3 & $\begin{array}{l}\text { I am interested in instilling moral values (respect, } \\
\text { brotherhood, love, and tolerance) among students. }\end{array}$ & 3.17 & 1.04 & 12 & Medium \\
\hline 10 & $\begin{array}{l}\text { I urge students to present their (psychological and } \\
\text { social) problems in order to solve them. }\end{array}$ & 3.14 & 0.31 & 13 & Medium \\
\hline 12 & $\begin{array}{l}\text { I am working on activating the daily supervision } \\
\text { program for students' attendance. }\end{array}$ & 3.01 & 0.82 & 14 & Medium \\
\hline 11 & $\begin{array}{l}\text { Make sure that my interaction with the students is } \\
\text { based on the positive approach and avoids any } \\
\text { punishment. }\end{array}$ & 2.92 & 0.44 & 15 & Medium \\
\hline
\end{tabular}

The results in Table (1) showed that the total score of the role of Jordanian secondary school teachers in educating students about electronic bullying from their point of view has been medium, with the total arithmetic average (3.51) with a standard deviation (0.64). In terms of arranging the paragraphs, it is clear from the table that paragraph (2) which stated "I strive to educate students about the safe handling of electronic technologies and means" has been mentioned in the first place in a large degree with an arithmetic mean (4.28) and a standard deviation (0.82), It is followed by paragraph (1), which states, "I make students aware of what cyberbullying is," with a great mean (4.01) and a standard deviation $(0.83)$. He also notes that paragraph (11) which states, "I make sure that my interaction with the students is based on the positive entrance and avoids any punishment procedure." It came in the last rank with an average score with an mean (2.92) and a standard deviation (0.440).

Results of the second question, which reads, "What are the difficulties facing Jordanian secondary school teachers in raising awareness of cyber bullying?

To answer the second question, arithmetic averages and standard deviations for paragraphs (16-26) mentioned in the study questionnaire were calculated. Table (2) shows the results of that.

Table (2) arithmetic averages and standard deviations of the difficulties that teachers face in educating students about electronic bullying

\begin{tabular}{|c|c|c|c|c|c|}
\hline \# & Paragraph & $\begin{array}{l}\text { Arithmetic } \\
\text { mean }\end{array}$ & $\begin{array}{l}\text { standard } \\
\text { deviation }\end{array}$ & Ranks & Availability \\
\hline 17 & $\begin{array}{l}\text { Student victim of bullying feared talking to } \\
\text { others that he had been bullied }\end{array}$ & 4.10 & 0.89 & 1 & High \\
\hline 16 & $\begin{array}{l}\text { The difficulty of knowing the personality of a } \\
\text { bully student via electronic means }\end{array}$ & 4.05 & 0.86 & $\begin{array}{l}2 \\
3 \\
4\end{array}$ & High \\
\hline 20 & $\begin{array}{l}\text { Parents have little control over their children's } \\
\text { behavior outside of school }\end{array}$ & 4.02 & 0.92 & 5 & High \\
\hline 21 & $\begin{array}{l}\text { Lack of students' awareness of the safe use of } \\
\text { technology }\end{array}$ & 3.94 & 1.00 & 6 & High \\
\hline 18 & Cyber bullying occurs outside the school & 3.87 & 0.93 & 7 & High \\
\hline 19 & Lack of awareness of what is cyberbullying & 3.82 & 0.94 & 8 & High \\
\hline 23 & The teachers away from the instructional role & 3.71 & 1.03 & 9 & High \\
\hline 22 & $\begin{array}{l}\text { Lack of students awareness of the dangers of } \\
\text { electronic bullying }\end{array}$ & 3.23 & 1.05 & 10 & Medium \\
\hline 24 & $\begin{array}{l}\text { The school's poor focus on raising awareness of } \\
\text { the phenomenon of cyberbullying. }\end{array}$ & 3.10 & 1.04 & 11 & Medium \\
\hline 26 & $\begin{array}{l}\text { Teachers' lack of sufficient information about the } \\
\text { phenomenon of cyberbullying }\end{array}$ & 2.91 & 0.78 & 12 & Medium \\
\hline 25 & $\begin{array}{l}\text { Weak promotion of the atmosphere of effective } \\
\text { dialogue in the classroom }\end{array}$ & 2.82 & 0.93 & 13 & Medium \\
\hline & Total Degree & 3.60 & 0.73 & \multicolumn{2}{|c|}{ Medium } \\
\hline
\end{tabular}

Table (2) shows arithmetic averages and standard deviations of the difficulties that teachers face in educating students about cyber bullying, and it is clear that the total score for these difficulties came as an average with an arithmetic mean (3.60) and a standard deviation (0.73). Paragraph (17), which stated, "The student's fear of being a victim of bullying from speaking to others that he was bullied" was ranked first in a large degree with an arithmetic average (4.10) and a standard deviation (0.89), Then paragraph (16), which stipulated "the difficulty of identifying the personality of a bully student via electronic means" in the second place to a large degree with an average score of (4.05) and a standard deviation (0.86). In the penultimate rank, paragraph (26) stated that "teachers 
lack sufficient information about the phenomenon of electronic bullying" with an average score of (2.91) and a standard deviation (0.78). As for paragraph (25), which stipulated "weakening the atmosphere of effective dialogue in the classroom," it came in the last place with an arithmetic average (2.82) and a standard deviation (0.93).

\section{Discuss the results:}

Discussing the results of the first question that reads, "What is the role of Jordanian secondary school teachers in educating students about cyber bullying from their point of view?

The results of the first question showed an average degree for the role of secondary school teachers in educating students of electronic bullying from their point of view, according to the appearance of some paragraphs with high levels and the emergence of some other paragraphs with medium degrees; which means that the role of teachers varied between these two levels.

It is noted that teachers 'assessments of the role they play in some aspects have come high, including their keenness to educate students about the need for safe dealing with electronic means and applications, and also to make them aware of what is electronic bullying, Perhaps these two points are the most important in the context of electronic bullying, as the student must be familiar with the intended electronic bullying in order to avoid it in the best way when dealing with electronic means and applications that are the means to spread electronic bullying. On the other hand, the results showed the interest of teachers in directing students towards more important alternatives than simply spending free time in the use of electronic means, including motivating students to do physical activities that emptied energies, enriched health, renewed vitality and activity. The results also showed that the teacher performs other activities that contribute to combating bullying by holding seminars inside the school and verifying behavioral and emotional disorders among students by relying on tests that perform this purpose. And on a medium degree, some of the paragraphs that are secondary came in spite of its importance such as ensuring the assessment of students' deviant behaviors, monitoring cases of electronic bullying, providing an educational environment based on mutual respect, and encouraging parents to attend discussions at the school about bullying, Promote effective dialogue, instill moral values among students, and activate daily supervision programs for student attendance, Dealing with students in a positive way and avoiding punishment all contribute to evaluating students' behavior and directing their behavior in a sound direction. As previously mentioned, these activities, and if the teacher does them, they do not fall on his own, but rather it is the responsibility of everyone inside and outside the school. Also, the phenomenon of electronic bullying is not limited to the student's presence in the school but also outside the school; therefore, the assessment of the teacher's role in these aspects with intermediate degrees does not reduce the positive role that the teacher plays in guiding students towards reducing the phenomenon of electronic bullying, In spite of the researchers 'interest in studying the phenomenon of electronic bullying, however, according to the researchers' knowledge, no studies have been reached to confirm or deny these results.

Discussing the results of the second question, which reads, "What are the difficulties facing Jordanian secondary school teachers in raising awareness of cyber bullying?

The results of the study on the difficulties that teachers face in educating students about electronic bullying showed that the overall degree of these difficulties was medium, and perhaps the reason for this is the variance of teachers 'estimates of the paragraphs used to measure these difficulties. It is noted from the results that one of the most important difficulties facing the teacher was the fear of the victim of bullying from speaking to others that he was bullied, The difficulty of knowing the personality of a bully student through electronic means, and this is consistent with the study (Al-Shennawi, 2014), which indicates that one of the most important difficulties that educators face in revealing electronic bullying is the difficulty of identifying the personality of the bully, This was justified by the fact that cyberbullying takes place inside and outside the school walls through cyberspace, and the lack of oversight by parents on the behavior of their children outside of school, Lack of awareness among students of the safe use of technology and lack of awareness of what is cyberbullying, teachers 'move away from the educational advisory role, and this is indicated by a study (Smith et al., 2008), It was explained that electronic bullying is often issued due to the absence of supervision by parents, teachers and school supervisors on students' behavior and following up changes in their behavior accurately. On the other hand, there are some items that appeared in moderate degrees, such as lack of awareness among students about the dangers of cyberbullying, The school's poor focus on raising awareness of the phenomenon of cyberbullying, and teachers 'lack of sufficient information on the phenomenon of cyberbullying, The weakening of the atmosphere of effective dialogue in the classroom. In the course of comparing the current results with the findings of previous studies regarding the difficulties that teachers face in educating students about the phenomenon of electronic bullying, For this result corresponds to a study that the researchers did not reach previous studies that clarify these difficulties.

\section{Recommendations:}

In the light of its results, the study recommends the following:

1. Enhancing the teacher's role in combating the phenomenon of electronic bullying by providing enough time 
outside classroom classes to educate students and motivate teachers to take this positive role.

2. Spreading the culture of fighting cyber bullying, so that everyone's responsibility inside and outside the school will include teachers and parents, as cyber bullying is not limited to inside the school, but it can happen outside of it with greater failure.

3. Encourage students to disclose the incidents of electronic bullying that they have been exposed to, because students' fear of speaking to others increases the phenomenon and makes it difficult for teachers or parents to deal with.

4. Educating parents about the negative effects of bullying and calling them to increase supervision of their parents' behavior outside of school.

5. Educating students about the safe use of electronic means and applications, and explaining the effects and risks they may be exposed to.

6. Carrying out future studies dealing with cyberbullying, using samples from teachers at various academic levels.

\section{Arabic references:}

Al-Zboon , Muhammad and Al-Zghoul, Muhammad (2016). A proposed educational program to reduce bullying among upper secondary stage students in Jordan, Journal of Studies and Research, 25 (8), 386-410.

El-Shennawy, Amina (2014). Psychometric proficiency for the electronic bullying scale (victim and bully), Journal of the Service Center for Research Consulting - Division of Psychological and Social Studies, Faculty of Arts - University of Menoufia, November number, 1-50.

Abdo, Asma Ahmad (2016). Psychological security and its relationship to bullying in adolescents. Journal of Scientific Research in Education, 17, 187-202.

Othman, Khaled and Ali, Ahmed (2014) Technological bulging of general education students, Journal of Psychological Studies, Egyptian Psychologists Association, 24 (2), 185-212.

Al-Assaf, Laila and Al-Sarayrah, Khaled (2010) The role of educational departments in addressing student violence behavior against teachers and administrators in government schools in Jordan, Journal of Educational Science Studies, 37 (1), 167-188.

Alwan, Imad (2016) forms of bullying in light of some demographic variables among adolescent students in the city of Abha, Journal of Education, Al-Azhar University - College of Education, 168 (1, 439-473).

Al-Ammar, Amal (2016) Cyberbullying and its relationship to internet addiction in the light of some demographic variables among students of applied education in the State of Kuwait, Journal of Scientific Research in Education: Ain Shams University, 17 (3), 223-249.

Al-Anzi, Manawir (2017) Cyberbullying on social media and its relationship to patterns of school violence, unpublished doctoral thesis, Naif Arab University for Security Sciences, Saudi Arabia.

Al-Qahtani, Noura (2015): Extent of awareness of bullying among female primary school teachers and the reality of the procedures used to prevent it in government schools in Riyadh from their point of view, Journal of Arab Studies in Education and Psychology, 58, 79-102.

Mohammadi, Fawzia and Khadda, Fatima Al-Zahra (2018) The effect of electronic violence in social media on social relations among young people: a study in Ouargla, Journal of Human and Social Sciences Generation: Generation Center for Scientific Research, 20, 47-55.

Nasser, Ibrahim (2011) Educational Sociology, Wael Publishing House: Amman, Jordan.

\section{Foreign references:}

Athanasiades, C., Kamariotis, H., Psalti, A., Baldry, A. C., \& Sorrention, A. (2015) Internet use and cyberbullying among adolescent students in Greece: the "Tabby" Project. Hellenic Journal of Psychology, 12, 14-39.

Baldry, A., Farrington, D. \& Sorrention, A. (2016) . Cyberbullying in youth: A pattern of disruptive behaviour. Psicologda Educative. 22, 19-26.

Baldry, A., Sorrentino, A. and Farrington, D. (2019). Cyberbullying and cyber victimization versus parental supervision, monitoring and control of adolescents' online activities. Children and Youth Services Review, 96, 302-307.

Brown, C. Demaray, M. \& Secord, S. (2014). Cyber victimization in middel school and relations to social emotional outcomes. Computers in Human Behavior, 35, 12-21.

Leung, A., Wong, N. and Farver, J. (2018). Cyberbullying in Hong Kong Chinese students: Life satisfaction, and the moderating role of friendship qualities on cyberbullying victimization and perpetration. Personality and Individual Differences, 133, 7-12..

Messias, E., Kindrick, K., and Castro, J. (2014) School bullying, cyberbulling, or both: Correlates of teen suicldallty in the 2011 CDC youth risk behavior survey. Comprehensive Psychiatry, 55(5), 1063-1068.

Ortega, R., Elipe, P., Mora-Merchán, J., Genta, M., Brighi, A., Guarini, A., Smith, P., Thompson, F. and Tippett, N. (2012). The emotional impact of bullying and cyberbullying on victims: A European cross-national study. Aggressive behavior, 38(5), 342-356. 
Quezada, R. and Romo, J. (2004). Multiculturalism, peace education and social Justice in teacher education. Multicultural Education, 11(3), 2-11.

Smith, P. K., Mahdavi, J., Carvalho, M., Fisher, S., Russell, S. and Tippett, N. (2008). Cyberbullying: Its nature and impact in secondary school pupils. Journal of child psychology and psychiatry, 49(4), 376-385.

Tokunaga, R. S.(2010). following you Home from School: A critral review and synthesis of research on cyberbullying victimization. Computers in Human behavior, 26, 277-287

Turner, M., Exum, M., Brame, R. Holt, T. (2013). Bullying victimization and adolescent mental health: General and typological effects across sex. Journal of Criminal Justice, 41(1), 53-59.

Acknowledgement:

The researchers would like to thank the respondents who participated in the present study 